\title{
Stress at work
}

\author{
@(థ) OPEN ACCESS
}

\section{Thomas Despréaux chief resident ${ }^{12}{ }^{3}$, Olivier Saint-Lary general practitioner ${ }^{4}$ senior lecturer ${ }^{4}$, Florence Danzin psychiatrist ${ }^{1}{ }^{6}$, Alexis Descatha occupational/emergency practitioner ${ }^{1}$ professor $^{1}$}

${ }^{1}$ Occupational health unit, University hospital of Poincaré site, Garches, France; ${ }^{2}$ Versailles St-Quentin University, Versailles, France; ${ }^{3} \mathrm{CESP}, \mathrm{U}$ 1018 Inserm, Villejuif, France; ${ }^{4}$ Versailles Saint-Quentin en Yvelines, Faculty of Health sciences Simone Veil, Department of Family Medicine, Montigny le Bretonneux, France; ${ }^{5}$ Université Paris-Saclay, University Paris-Sud, Villejuif, France; ${ }^{6}$ Charcot Psychiatric Hospital, France

\begin{abstract}
A 55 year old senior executive presents with low back pain. He appears anxious. A reorganisation within his company has increased his workload and he has been working more hours but receiving no recognition from management. Last week he felt humiliated by a colleague. Since then he has not been able to sleep for more than a couple of hours each day.

Stress accounts for more than a third of all cases of work related ill health and almost half of all working days lost due to illness. ${ }^{1}$ Internationally, systematic reviews and meta-analysis of observational data suggest that job strain and poorly functioning work environments are associated with the development of depressive symptoms. ${ }^{2-4}$ A longitudinal cohort study from Norway found workplace bullying to be associated with subsequent suicidal ideation. ${ }^{5}$ Long working hours are also associated with increased risk of stroke, heart disease, ${ }^{6}$ and diabetes, ${ }^{7}$ and poor lifestyle including inactivity, ${ }^{7}$ smoking, ${ }^{7}$ and risky alcohol use. ${ }^{8}$

Patients might present with unexplained somatic symptoms, such as odd aches and pains, palpitations, loss of appetite, and loss of sleep. ${ }^{9}{ }^{10}$ Explore their symptoms and discuss any contributing factors in their work and personal life. The consultation can be long and difficult, as the patient might not volunteer all the information or draw the association with work stress. The objective of this first consultation is to perform a quick risk assessment and explore factors in the patient's job that are contributing to stress.
\end{abstract}

\section{What you should cover}

The following questions are based on systematic reviews, and the experiences of clinicians and patients.

\section{Ask about}

- the nature and duration of the patient's presenting symptoms
- associated depressive symptoms, such as

o feeling down, low, or sad

o loss of interest in activities

o tiring easily

o lack of concentration

o changes in sleep and appetite

- feelings of hopelessness, (eg, a belief that the situation cannot improve $)^{11}$

- occupation, working environment, and stressors at work (box 1)

- the chronology of events, how the patient has coped so far, and if things have changed recently in their workplace. Typically, three phases are described ${ }^{13}$ :

an initial ("serene") phase, where the patient reports no particular difficulty

a "problem" phase, when obstacles and conflicts gradually appear and the patient tries to deal with the situation

a "crisis" phase, where s/he comes to see you

- protective factors for severity of outcome include a supportive family environment and financial wellbeing. Aggravating factors are familial isolation, being a single parent with young children, having financial difficulties, or being bound by a particular type of employment contract that forces the patient to stay in the same job. The latter can delay diagnosis, and limit the range of remedial options available.

- thoughts of ending their life or causing harm to themselves or others

- other medical illnesses, including diabetes, hypertension, cardiovascular events, or psychiatric disorders 


\section{What you need to know}

- Long working hours and strain at work contribute to stress, ill health, and increased risk of cardiovascular diseases, diabetes, and mental illnesses

- Explore occupational factors such as an imbalance between effort and reward, work overload, bullying, and job insecurity

- Workplace interventions, a short period of leave from work, and psychological treatment can be considered, alongside regular follow-up to assess how the patient is coping

- smoking, alcohol, and drug abuse

- family history of depression or mental disorders, which could increase the risk of depression and suicide

Patients come to their doctor primarily to address their symptoms, but some will also want assistance and advice on how to cope with the situation at work.

\section{Examination}

Assess general appearance and look for signs of psychomotor agitation such as restlessness, rapid talking, and racing thoughts, or of psychomotor retardation such as apparent exhaustion and visible slowing of physical activity. These might indicate a mental illness or organic cause, such as a thyroid disorder.

Perform a quick general examination to look for fever, tachycardia, hypertension, and signs of thyroid disorder (which can be a differential diagnosis). Examine thoroughly for reported pain, though somatisation is likely.

\section{What you should do}

Investigation and management of physical and mental health diagnoses - Offer usual management of conditions such as depression. Consider immediate referral to psychiatry if the patient describes suicidal or aggressive thoughts or intentions.

Make the connection between the patient's experience and work stress-For patients with work related stress and a variety of symptoms, acknowledge their situation and validate their feelings with a phrase such as, "I understand that you are suffering and that this feeling is arising from a stressful work environment."

Offer a supportive setting to discuss and make progress in dealing with work stress - High quality evidence and guidelines for interventions to manage work related adjustment issues and stress are lacking. ${ }^{14}$ Cognitive therapy, stepwise reintegration planning, and relaxation training can all be considered. ${ }^{15} 16$ Therapy needs to be supportive, active, flexible, goal directed, and time bound..$^{10-14}$

Consider offering a second appointment-for example, if there is too much to cover. You might suggest that the patient brings a family member to the next appointment for support.

In the interim, you might ask the patient to reflect on their job and personal situation, and possibly to write a short description of their problems at work, the chronology of these problems, and their relationship to the patient's symptoms. In our experience, some patients find this helps them reflect on the events, and it can help you understand their situation better. This will help to initiate discussion on strategies that the patient might employ to navigate their workspace going forward. Making contact with the workplace to modify work or reduce workload in collaboration with the employer can be helpful. Discuss whether the occupational health services or human resources division at the patient's company could be involved. In some circumstances, patients might wish to seek compensation or take legal action. Explore if these are important for your patient and direct them to appropriate agencies or lawyers who can help with these matters.
Consider whether the patient wants or might benefit from time away from work including a "sick note."

Schedule a follow-up visit to assess how the patient is coping with symptoms and workplace issues, and modify the approach accordingly.

We would like to thank Richard Carter for helping us to improve the language of this document.

We have read and understood BMJ policy on declaration of interests and declare that we have no competing interests.

We would like to thank Richard Carter for helping us to improve the language of this document.

Patient consent obtained.

Statistics-Work related stress, anxiety and depression statistics in Great Britain (GB). http://www.hse.gov.uk/statistics/causdis/stress

2 Theorell T, Hammarström A, Aronsson G, et al. A systematic review including meta-analysis of work environment and depressive symptoms. BMC Public Health 2015;15:738. doi:10.1186/s12889-015-1954-4. pmid:26232123.

3 Rugulies R, Aust B, Madsen IE. Effort-reward imbalance at work and risk of depressive disorders. A systematic review and meta-analysis of prospective cohort studies. Scand $J$ Work Environ Health 2017;17:3632. doi:10.5271/sjweh.3632. pmid:28306759.

4 Harvey SB, Modini M, Joyce S, et al. Can work make you mentally ill? A systematic meta-review of work-related risk factors for common mental health problems. Occup Environ Med 2017;74:301-10. doi:10.1136/oemed-2016-104015. pmid:28108676.

5 Nielsen MB, Einarsen S, Notelaers G, Nielsen GH. Does exposure to bullying behaviors at the workplace contribute to later suicidal ideation? A three-wave longitudinal study. Scand J Work Environ Health 2016;42:246-50. doi:10.5271/sjweh.3554. pmid:27135593.

6 Kivimäki M, Jokela M, Nyberg ST, et al. Long working hours and risk of coronary heart disease and stroke: a systematic review and meta-analysis of published and unpublished data for 603838 individuals. Lancet 2015;386:1739-46. doi:10.1016/S0140-6736(15) 60295-1

7 Nyberg ST, Fransson El, Heikkilä K, et al. Job Strain and Cardiovascular Disease Risk Factors: Meta-Analysis of Individual-Participant Data from 47000 Men and Women. Testa L, ed. PLOS ONE 2013;8:e67323. doi:10.1371/journal.pone.0067323

8 Virtanen M, Jokela M, Nyberg ST, et al. Long working hours and alcohol use: systematic review and meta-analysis of published studies and unpublished individual participant data. BMJ 2015;350:g7772. doi:10.1136/bmj.g7772

9 American Psychiatric Association. Diagnostic and Statistical Manual of Mental Disorders. 5th ed (DSM-5). American Psychiatric Publishing 2013.

10 van der Klink JJL, van Dijk FJH. Dutch practice guidelines for managing adjustment disorders in occupational and primary health care. Scand $J$ Work Environ Health 2003;29:478-87. doi:10.5271/sjweh.756pmid:14712856.

11 Fraser L, Burnell M, Salter LC, et al. Identifying hopelessness in population research: a validation study of two brief measures of hopelessness. BMJ Open 2014:4:e005093. doi: 10.1136/bmjopen-2014-005093. pmid:24879829.

12 Nieuwenhuijsen K, Bruinvels D, Frings-Dresen M. Psychosocial work environment and stress-related disorders, a systematic review. Occup Med (Lond) 2010;60:277-86. doi:10. 1093/occmed/kqq081. pmid:20511268.

13 Mediouni Z, Garrabé $\mathrm{H}$, Jaworski $\mathrm{F}$, et al. Initial evaluation of patients reporting a work-related stress or bullying. J Occup Environ Med 2012;54:1439-40. doi:10.1097/JOM. 0b013e31827942e0. pmid:23222476.

14 Joosen MCW, Brouwers EPM, van Beurden KM, et al. An international comparison of occupational health guidelines for the management of mental disorders and stress-related psychological symptoms. Occup Environ Med 2015;72:313-22. doi:10.1136/oemed-2013101626. pmid:25406476

15 West CP, Dyrbye LN, Erwin PJ, Shanafelt TD. Interventions to prevent and reduce physician burnout: a systematic review and meta-analysis. Lancet 2016;388:2272-81. doi:10.1016/S0140-6736(16)31279-X. pmid:27692469.

16 Van den Broeck K, Remmen R, Vanmeerbeek M, Destoop M, Dom G. Collaborative care regarding major depressed patients: A review of guidelines and current practices. J Affect Disord 2016;200:189-203. doi:10.1016/j.jad.2016.04.044. pmid:27136418.

Published by the BMJ Publishing Group Limited. For permission to use (where not already granted under a licence) please go to http://group.bmj.com/group/rights-licensing/ permissions

This is an Open Access article distributed in accordance with the Creative Commons Attribution Non Commercial (CC BY-NC 4.0) license, which permits others to distribute, remix, adapt, build upon this work non-commercially, and license their derivative works on different terms, provided the original work is properly cited and the use is non-commercial. See: http://creativecommons.org/licenses/by-nc/4.0/. 


\section{Box 1: Occupational factors for stress ${ }^{2-13}$}

Conflict of values (being asked to do a poor quality job or cut costs for a person who likes to keep high standards in their work) Feeling insufficiently rewarded compared with the person's assessment of their efforts ("effort-reward imbalance")

Inability to make decisions about when or how to stop work

Lack of support from colleagues and management

Isolation at work (no cooperation between teams)

Work overload (working after hours) or insufficient workload (nothing to do)

Discrimination, humiliation, violence, bullying, and harassment at work

Cases of work related stress in the same company

Company situation in terms of finances, organisational changes, and employee turnover

Job insecurity, temporary employment status

\section{Education into practice}

- What factors would you typically explore in the patient's history to understand their working environment and stress? Does this article offer you ideas on how to do so differently?

- Sometimes, asking the patient to write down their problems at work, the times at which the problems occurred, and the patient's symptoms, is helpful. Are there ways in which you might consider using this or other techniques to help patients better organise their thoughts or understand them yourself?

- Do you offer a second appointment, if there is too much to cover, or if the patient wishes to include a friend or family member?

- In difficult cases, do you work in collaboration with mental health professionals as well as occupational health professionals?

\section{How patients were involved in the creation of this article}

Patients in our practice reported a need to rethink what they had experienced at work and to share this in writing. This helped them identify and clearly communicate the chronology of events. Based on their feedback we recommend encouraging patients to write about their work environment and factors contributing to stress, though this need not be mandatory.

A patient reviewed this article and attested that writing a two page memorandum would have been enormously helpful to identify problems at work and how they had escalated over time, and to come to terms with the situation. 